\title{
A Experiência Drag Queen como Transição na Vida Adulta
}

\author{
Ligia Ribeiro Ferreira* \\ Universidade Federal de Pernambuco - UFPE, Recife, PE, Brasil \\ ORCID: https://orcid.org/0000-0002-0739-380X \\ Renata Lira dos Santos Aléssio** \\ Universidade Federal de Pernambuco - UFPE, Recife, PE, Brasil \\ ORCID: https://orcid.org/0000-0001-8548-2771
}

\begin{abstract}
RESUMO
A partir de reflexões teóricas impulsionadas pela Rede de Significações (RedSig) e Teorias de Gênero, o presente trabalho teve como objetivo investigar sentidos e significados tecidos sobre a experiência como drag queen na vida adulta. A metodologia utilizada teve base em entrevistas biográficas, realizadas com cinco participantes, entre 20 e 39 anos, que têm ou já tiveram experiência como drag queens. Para a análise, foi realizada uma abordagem microgenética, correlacionando elementos da RedSig com as narrativas. Os resultados indicaram que a vida adulta não aparece como percurso linear, sendo permeada por rupturas, conflitos e negociações de sentidos e posições. A vida adulta se torna o palco no qual é possível ocupar determinados espaços de poder para colocar em prática desejos e curiosidades que, por vezes, remontam à infância. A drag queen emerge como um elemento relacionado a esse processo, atrelada a diversos sentidos e significados positivos (arte, realização, liberdade) e negativos (vergonha, preconceito, degradante).
\end{abstract}

Palavras-chave: drag queen, psicologia do desenvolvimento, vida adulta, transição, RedSig.

\section{The Drag Queen Experience as a Transition in Adult Life}

\begin{abstract}
From theoretical reflections driven by the Network of Meanings and Gender Theories, this work aims to investigate senses and meanings constructed on experience as a drag queen in adult life. The methodology used was based in biographical interviews, carried out with five participants, between 20 and 39 years of age, who have or already had experience as drag queens. For the analysis, a microgenetic approach was performed, correlating elements of the Net of Meanings with the narratives. Adulthood does not appear as a linear course, being permeated by ruptures, conflicts and negotiations of meanings and positions. Adulthood becomes the stage on which it is possible to occupy certain spaces of power to put into practice desires and curiosities that sometimes go back to childhood. The drag queen emerges as an element related to this process, tied to several positive (art, accomplishment, freedom) and negative (shame, prejudice, degrading) senses and meanings.
\end{abstract}

Keywords: drag queen, developmental psychology, adulthood, transitions, network of meanings. 


\section{La Experiencia Drag Queen como Transición en la Vida Adulta}

\section{RESUMEN}

A partir de reflexiones teóricas estimuladas por la Red de Significaciones (RedSig) y Teorías de Género, el presente trabajo tuvo como objetivo investigar sentidos y significados construidos sobre la experiencia como drag queen en la vida adulta. La metodología utilizada tuvo como base entrevistas biográficas, realizadas con cinco personas, entre 20 y 39 años, que tienen o ya han tenido experiencia como drag queens. Para el análisis, se realizó un enfoque microgenético, correlacionando elementos de la RedSig con las narrativas. La vida adulta se convierte en el escenario en el que es posible ocupar ciertos espacios de poder para poner en práctica los deseos y curiosidades que a veces se remontan a la infancia. La drag queen surge como un elemento relacionado con este proceso, vinculado a varios sentidos y significados, positivos (arte, logro, libertad) y negativos (vergüenza, prejuicio, degradante).

Palabras clave: drag queen, psicología del desarrollo, vida adulta, transición, RedSig.

Drag queen ou transformista é o termo designado a artistas que personificam o feminino de forma exagerada e estereotipada, através da utilização de roupas, acessórios, maquiagem entre outros (Jesus, 2012). Ressalta-se que esta expressão se dá de forma plural, podendo ser interpretada de outras formas por outros a(u)tores. No presente trabalho, entendese a drag queen enquanto uma expressão artística, relacionada à construção de uma personagem. Nesse sentido, é importante ressaltar que a drag queen se diferencia da identidade de gênero, tendo em vista que não se trata de uma identidade, mas sim, de uma persona assumida momentaneamente. Compreende-se, ainda, que essa é uma experiência possível a qualquer pessoa, independentemente de sua orientação sexual ou identidade de gênero. A orientação sexual refere-se à atração e conduta afetivo sexual (Jesus, 2012), enquanto a identidade de gênero refere-se à forma pela qual a pessoa se identifica, e pode ser diferente do gênero designado no nascimento. Assim, orientação sexual e identidade de gênero são instâncias independentes (Jesus, 2012). Nesse panorama, foram entrevistadas pessoas que autodeclaram como artistas drag queens, independentemente de sua identidade de gênero e orientação sexual.

Atrelando a drag queen ao teatro e à performance, Amanajás (2015) remonta a história do personificador do feminino a tempos remotos, mostrando que na Grécia Antiga e ainda no século XVI, na Inglaterra, havia a interdição da participação feminina no palco. Na Inglaterra, por exemplo, os papéis femininos criados por Shakespeare eram interpretados por homens. Especula-se que, nesses casos, o autor colocava em seus manuscritos a expressão dressed as girl (do inglês, "vestido como menina"), que teria dado origem ao acrônimo drag (Amanajás, 
2015). Gradualmente, as mulheres vão sendo encaradas com maior seriedade em suas habilidades cênicas, e os homens que personificam o feminino passam a fazê-lo por motivos cômicos, com exceção da Ópera, que mantém a seriedade (Amanajás, 2015). No século XIX, a drag tem seu caráter cômico e caricatural ratificado, configurando-a como uma prática comum aos comediantes da época. Nesse contexto, passa a unir componentes de outras expressões artísticas como o clown e o stand up, o que ainda reverbera nas performances da atualidade.

Com o advento da cultura pop, expandem-se as possibilidades dos artistas performadores do feminino, assim como as suas influências e inspirações. $\mathrm{O}$ autor coloca, ainda, que na década de 1980 a epidemia da Acquired Immunodeficiency Syndrome (AIDS) reconfigura as relações sociais, e as drag queens são marginalizadas, tendo seu espaço restrito a bares gays. Isso gerou uma associação entre a cultura Lésbicas, Gays, Bissexuais, Travestis, Transexuais e Transgêneros (LGBT) e a figura da drag que ainda permanece nos dias atuais. Nesse panorama, solidificou-se o seu papel político, tendo em vista a subversão e o questionamento dos padrões de gênero da sociedade.

No Brasil, a drag queen remonta à década de 1970. As Dzi Croquettes, grupo teatral formado exclusivamente por homens que faziam uso de elementos atrelados à feminilidade, como o sapato de salto, vestidos e maquiagem, surgem em plena ditadura, alcançando reconhecimento internacional. Esse grupo pode ser compreendido como precursor da drag queen no país. Na década de 1990, no sul do país, a arte desponta junto à cultura pop, tendo vários nomes como Silvetty Montila e Nany People (Amanajás, 2015). Observa-se, portanto, que a figura da drag queen se reconstrói a partir de acontecimentos sociais, permeando diversos espaços, estéticas e discursos.

Ainda hoje, a drag queen diz respeito a experiências que se dão de forma plural, sendo possíveis diversas formas de construção e expressão, inclusive com propostas que misturem e confundam os gêneros. Entre as particularidades das drags, Vencato (2010) coloca corporalidade, teatralidade e temporalidade. A corporalidade aparece por meio de elementos como acessórios e maquiagem; o teatro emerge na questão da personagem e dos excessos; e a temporalidade é marcada no jogo antes/durante/depois da montação - processo de transformação do corpo, através de técnicas e truques (Louro, 2004), como maquiar-se e vestir-se para montar a figura do feminino.

Zimovski e Caeiro (2016) mostram que entre as práticas características da arte drag queen estão a dublagem de músicas (lipsync) e o denominado "bate cabelo", técnica de dança criada nos anos 1990 por Márcia Pantera, que envolve o molejo de cabeça e corpo para que os 
cabelos da peruca ganhem movimento no ar. Tais performances são marginalizadas socialmente, ainda conectadas aos sentidos negativos associados às homossexualidades. Nesse sentido, corrobora-se o caráter político da montação, uma vez que questiona a polarização dos gêneros e provoca estranhamento (Amanajás, 2015).

Butler (2008) entende o gênero como uma cristalização que se dá pela reiteração de normas por diversos meios sociais, e, nesse sentido, figuras como a drag queen confrontam esse status quo. Sendo caracterizadas pela autora como paródias de gênero, essas pessoas teatralizam um outro, e tensionam a ideia de um gênero original que decorre do sexo. Ele se apresenta enquanto um lócus imitativo, em que são copiados gestos, falas, posturas, num processo explícito de construção de um gênero, o como ser "mulher", no caso de personificadores do feminino. Ainda de acordo com a autora, a organização social do gênero se dá de forma binária e polarizada em masculino e feminino, sem considerar outras possibilidades de expressão de gênero, o que é denominado de binarismo de gênero. Essa ideia se pauta numa correlação direta que se estabelece com o sexo: homem-masculino e mulher-feminino (Butler, 2008), gerando expectativas sociais que se mantêm nessa linearidade, sendo a expressão drag queen uma quebra desta última, uma vez que se apresenta, muitas vezes, como a "ultrapassagem" de um gênero ao outro, a exemplo do homem que se veste de mulher.

As teorias de gênero, fundamentadas no pós-estruturalismo, dão ênfase ao caráter contínuo da construção da pessoa, que se dá em relação com o meio e com a sociedade. Podese relacionar a montação da drag queen com uma posição assumida pela pessoa, que ocorre em suas trocas e negociações com os outros e com as práticas sociais existentes. Com base nessa concepção de pessoa em constante mutação, optou-se por abordar a experiência como drag queen na vida adulta, sob o prisma da psicologia do desenvolvimento. Visto que a Rede de Significações é uma perspectiva que compreende o desenvolvimento como um processo contínuo e multifacetado (Rosetti-Ferreira, Amorim, \& Silva, 2004), esta perspectiva mostrou-se como um válido alicerce, que pode auxiliar na compreensão de como as pessoas significam a drag queen.

A Rede de Significações se baseia numa compreensão do desenvolvimento humano como um processo singular, que ocorre "nas e por meio das múltiplas interações" culturais (Rosetti-Ferreira et al., p. 23) decorrentes de elementos diversos como a pessoa, os contextos, a matriz sócio-histórica, entre outros. É, portanto, uma perspectiva que quebra com a ideia atomística de desenvolvimento, assim como com sua visão homogênea e linear, e coloca-o como um processo multidimensional, multiplural e inseparável do contexto. A metáfora da 
rede surge como modo de ilustrar que o desenvolvimento humano só se estabelece a partir de relações, visto que está imerso numa malha semiótica de elementos que dialogam entre si, e que por sua complexidade e dinamicidade formam redes que permitem a construção dos mais variados sentidos (Rosetti-Ferreira et al., 2004). De forma dialógica, são esses próprios sentidos - atribuídos a si e ao mundo - que constroem o domínio semiótico que se concretiza nas interações (Amorim, Vitoria, \& Rosetti-Ferreira, 2000).

Como trazido por Smolka (2004), a significação é um processo inerente ao ser humano, que sempre busca dar sentidos às suas ações. Dessa forma, a existência humana é permeada pela linguagem, que as transforma e permite um redimensionamento dessas através da cultura. Os sentidos se darão a partir de uma construção contínua e conjunta e, nesse jogo, sempre poderão ser plurais. Assim como há a possibilidade de existir algo em comum, também há um componente de diferenciação, visto que essas construções serão experienciadas de forma singular.

Nesse sentido, ao trazer a ideia de pessoa, Rosetti-Ferreira et al., (2004) ressaltam o caráter relacional de sua constituição. Entende-se que as relações sociais são fundantes durante toda a vida, visto que permitem a assemelhação e diferenciação, e é nesse interjogo que são construídas as identidades pessoais e grupais. Ao serem designados papéis/posições, as pessoas podem assumi-los, negá-los, ou ressignificá-los, o que lhes permite novas possibilidades no desenvolvimento e faz delas não um produto, mas um processo contínuo (Amorim et al., 2000). Assim, a singularidade é garantida, uma vez que se torna impossível que duas pessoas façam o mesmo percurso negociando os mesmos sentidos e significados.

Ao situar as relações sociais, percebe-se que elas não ocorrem isoladamente, estando atreladas à história, sistema de valores, economia, política, cultura, entre outros. Tendo em vista essas associações, torna-se relevante pontuar que os contextos não devem ser encarados como "panos de fundo" (Rosetti-Ferreira et al., 2004, p. 26), mas sim como constituintes e constituídos nas interações. Evidencia-se que esses só podem ser considerados a partir de sua relação com as pessoas, que concomitantemente serão sujeitadas às suas características e atuarão no sentido de transformá-los e ressignificá-los.

Da mesma forma, a matriz sócio-histórica - âmbito mais amplo que atravessa os contextos - vai ser visualizada a partir de um olhar relacional com a pessoa. Entendendo-a como uma formação múltipla, que abrange elementos culturais, sociais, históricos, entre outros, vai se configurar de maneira heterogênea, o que reverbera no caráter semiótico dessa, gerando a existência de múltiplas vozes, que por vezes são contraditórias, mas que permitem uma maior plasticidade no processo de desenvolvimento. Em termos concretos, a matriz 
sócio-histórica pode ser observada por meio de como se organizam as práticas sociais, os discursos e os espaços. Dessa maneira, pode-se vincular os níveis micro e macro sociais (Rosetti-Ferreira et al., 2004).

É possível que esse contexto promova a emergência de confrontos e crises - no exemplo dessa pesquisa, divergência entre a posição assumida enquanto drag queen e a expectativa social de gênero - e a RedSig entende que essas situações de conflitos também fazem parte da constituição pessoal (Rosetti-Ferreira et al., 2004). Outro significativo aspecto considerado pelo prisma da RedSig é a noção de circunscritores. Tendo em vista que as redes podem configurar-se de modos plurais e potencializam trajetórias diversas, ressaltam-se também suas limitações e restrições, enquadradas em um determinado contexto. Assim, os circunscritores atuam como reguladores desse processo, em um jogo entre previsibilidade e imprevisibilidade do/no desenvolvimento. Adquirindo uma natureza física ou simbólica, os circunscritores fundamentam crenças, visões sobre o mundo e sobre si mesmo, e se mantêm em constante (re)construção, o que dá abertura para a formação de novos sentidos. Os circunscritores se encontram relacionados e refletem relações de poder, podendo se apresentar de modo hierarquizado (Silva, Rossetti-Ferreira, \& Carvalho, 2004).

A experiência drag queen é uma prática que foge à expectativa social, pode, portanto, estar atrelada a pontos de viragem. Pontos de viragem são transformações relevantes na vida da pessoa que lhe permitem alternativas além do que é tido como possibilidade no meio cultural (Oliveira \& Rego, 2006). Mendonça (2006) ressalta que os pontos de viragem não se tratam de uma passagem de um estágio de vida para o outro, mas sim de situações que podem ocorrer a qualquer momento da vida do indivíduo, visto que se relacionam com o imprevisto e o improvável, sendo caracterizados como momentos de tensão, ruptura ou crises. Na vida adulta, esses estão associados a um novo modo de pensar e organizar a vida mais do que a rituais institucionalizados socialmente, tais como o casamento e a independência financeira.

Nos contextos de interação em que ocorrem descontinuidades e/ou rupturas, as pessoas recorrem a novos dispositivos simbólicos para ajustar-se à situação. Esses novos dispositivos, portanto, constituem-se como recursos que permitem que o agente da situação faça uma transição de uma formação sociocultural para outra (Zittoun, Duveen, Gillespie, Ivinson, \& Psaltis, 2003). Ainda sobre transições, Zittoun (2007) argumenta que essas envolvem três processos interdependentes, sendo eles: (1) mudanças sociais, materiais ou simbólicas na experiência da pessoa, implicando processos de reposicionamento ou relocação nos campos simbólico e social. Essas mudanças podem trazer novas orientações, objetivos, limites e possibilidades, assim como perdas e incertezas, traçando, inclusive, mudanças identitárias; (2) 
desenvolvimento de novos conhecimentos e habilidades sociais e cognitivas; (3) construção de significados, dando sentido à sua trajetória, o que compreende a narrativização da experiência no sentido de manter uma continuidade e consistência de suas vivências.

Processos ligados a transições estão também ligados a rupturas e à emergência de algo não esperado. Nessas ocasiões, há uma espécie de catalisação da construção de significados, visto que as pessoas "perdem" o território conhecido de sentidos, sendo impulsionadas a recriar sentidos e significados (Zittoun et al., 2003). Ainda de acordo com ela, essas rupturas podem se dar na história pessoal, na relação com outros ou na presença de um objeto desconhecido, a exemplo da drag queen.

Com base nas reflexões feitas, o objetivo do estudo foi investigar os sentidos e significados tecidos sobre a experiência como drag queen na vida adulta. A partir disso, estabeleceram-se relações com diversos elementos da RedSig presentes no desenvolvimento, bem como com processos de transição, que se referem a novas formas de dialogar com a vida e suas possibilidades.

\section{Método}

A RedSig busca abordar os fenômenos complexos de forma integrativa, considerando os diferentes âmbitos que se relacionam de forma sistêmica. Devido a essa complexidade, muitas vezes são realizados recortes temáticos (Rossetti-Ferreira et al., 2004), aqui ilustrados pela vivência como drag queen. No intuito da construção do campo, a pesquisadora aproximou-se de locais e contextos atrelados à $d r a g$, tais quais boates, performances, plataformas digitais, seriados, cursos de montação, entre outros. Através dessa imersão, foi possível acessar as pessoas que participaram deste estudo.

\section{Participantes}

A amostra foi composta por cinco participantes, sendo quatro homens cisgêneros homossexuais e uma mulher cisgênera heterossexual, que tiveram ao menos uma experiência de montação e se identificam como drag queens. Cisgênero ou "cis" é o termo designado às pessoas que se identificam com a identidade de gênero que lhes foi atribuída no nascimento. A faixa etária variou entre 20 e 39 anos. É importante destacar que, apesar de não ser o objetivo do presente estudo, todas as pessoas entrevistadas tiveram uma trajetória acadêmica. Com o intuito de resguardar as identidades, os nomes pessoais e das drags são fictícios. 
Reconhecendo a centralidade e complexidade do processo de nomeação da drag queen, os nomes foram construídos a partir de elementos das histórias singulares dos participantes, resgatando episódios vividos e referências pessoais citadas, de forma que mantivessem uma conexão com suas trajetórias e ao mesmo tempo garantissem o sigilo de seu nome artístico. Aos participantes, pediu-se que narrassem momentos importantes de suas vidas que se relacionassem com a drag queen, buscando as trocas entre o "eu" e a personagem. Apresentase de forma sucinta os participantes entrevistados a seguir:

Daniel, homem cisgênero, homossexual, 22 anos. Começou a se montar há cerca de um ano e oito meses quando realizada a entrevista. Afirma ter se identificado desde cedo com referências associadas à feminilidade, porém teve uma educação conservadora, baseada na religião Cristã, chegando a reproduzir alguns discursos normativos. Após a entrada na Universidade, interessou-se pela figura do Female Impersonator, e mais tarde, pela figura da drag queen, começando a se montar como a Imperatriz Kawaii, com o intuito de compor o seu Trabalho de Conclusão de Curso (TCC).

Rosa, mulher cisgênera, heterossexual, 39 anos. Começou a se montar há cerca de um ano e meio/ dois anos no momento da entrevista. Afirma ter sido muito sonhadora na infância, mas se sentiu muito oprimida pela família, o que também aconteceu na adolescência e em parte da vida adulta, chegando a ter tido dois relacionamentos amorosos abusivos. Mais recentemente, declara que vive uma fase de libertação, na qual conheceu o atual companheiro e também emergiu a sua drag, Kira Heart.

Paulo, homem cisgênero, homossexual, 28 anos. Começou a se montar na adolescência, mas situa, ao ser entrevistado, o nascimento de sua drag há cerca de 6/7 anos. Diz ter sentido curiosidade por objetos ditos femininos desde a infância, em que vestia o vestido e sapatos da mãe escondido. Na adolescência, começa a frequentar novos espaços e começa a se montar, passa a trabalhar no meio da saúde através da personagem, e, aos poucos, sua drag é transformada: nasce Sheyla Áquila.

Marcos, homem cisgênero, homossexual, 31 anos. Começou a se montar há cerca de 6 anos. Afirma ter nascido no interior e ter tido uma educação conservadora, mas ter se reconhecido enquanto LGBT desde cedo. Mais velho, quando se mudou para Recife, 
se declarou como homossexual para a família. Mais tarde, entrou em contato com elementos da cultura LGBT, tal como a série estadunidense RuPaul's Drag Race reality show, lançada em 2009, composta inteiramente por drag queens, que competem pelo título de “America's Next Drag Superstar” - e começou a questionar os padrões de gênero, decidindo começar a se montar como Miss Tiffany.

Vitor, homem cisgênero, homossexual, 20 anos, solteiro. Começou a se montar há 4 anos. Envolvido com teatro desde a escola, diz ter sentido curiosidade desde cedo para objetos ditos do universo feminino, mas sempre foi advertido ou impedido por outras pessoas de experimentá-los. Ao entrar na faculdade começou a se questionar sobre isso e começa a se montar como Julieta.

\section{Instrumentos e procedimentos de coleta}

Com o intuito de identificar e contatar os entrevistados, foi utilizada a técnica de amostragem "bola de neve". As entrevistas tiveram início a partir de um informante-chave, que indicou outros contatos a partir de sua própria rede pessoal (Vinuto, 2014). A coleta foi realizada através de entrevistas autobiográficas, que buscaram investigar os significados e sentidos atrelados à drag queen, analisando possíveis transformações relacionadas à vivência. A partir de um recorte situado no momento da entrevista (tempo presente), foram despertadas vozes das outras dimensões temporais, permitindo que essas se fizessem presentes (RosettiFerreira et al., 2004). Como colocado por Bruner (2004), a narrativa autobiográfica é entendida como um procedimento de "construção da vida", visto que é a partir dela que as pessoas interpretam e reinterpretam a experiência, que se tornam as histórias de suas vidas. Não se trata apenas de relatar o óbvio ou o factual, mas sim de um empreendimento cognitivo, no qual se configura uma narrativa com personagens, elementos e fatos que se associam, a partir da perspectiva do narrador. Considerando que estão inseridas numa cultura, as histórias vão tomar formas possíveis dentre as alternativas culturais, estando suscetíveis às influências culturais, interpessoais e linguísticas (Bruner, 2004). São trazidos conjuntos de sentidos e significados construídos culturalmente, o que permite uma aproximação com os atravessamentos históricos e culturais internalizados pelo sujeito em um determinado contexto, época e sociedade (Oliveira \& Rego, 2006).

Antes de iniciar a coleta, foi pedido aos participantes para ler e assinar, caso concordassem, com o Termo de Consentimento Livre e Esclarecido (TCLE). Em seguida, 
pediu-se que colocassem em um papel A3 experiências importantes de suas vidas que de alguma forma se relacionavam com a sua drag queen, deixando-lhes livres para desenhar, escrever, fazer uma linha do tempo, entre outros. O tempo para essa atividade também era livre. Posteriormente, foi pedido para contar um pouco da história de suas vidas, trazendo em sua narrativa os elementos colocados no papel. As entrevistas foram gravadas em áudio e integralmente transcritas pela pesquisadora para posterior análise. Essas atividades foram realizadas em um único encontro com cada participante, tendo cerca de 60 a 100 minutos cada encontro. As entrevistas gravadas duraram de 40 a 65 minutos. O local e horário foram acordados entre participante e pesquisadora, buscando ambientes reservados e silenciosos, variando entre instituições acadêmicas e moradia dos entrevistados.

\section{Análise dos dados}

A entrevista biográfica permitiu a estruturação de uma narrativa no aqui-agora da relação pesquisadora-pesquisado, o que se mostrou como um campo frutífero de análise. A partir de uma análise microgenética, foram traçadas relações com elementos da Rede de Significações, tais como a pessoa, campo interativo dialógico, circunscritores, matriz sóciohistórica, contextos e temporalidades. Através de uma contextualização rigorosa, bem como de um extenso trabalho de ir e vir no corpus, atrelado a um constante diálogo com as teorias que fundamentam esse estudo, enfatizou-se também os processos de mudança e transformação, com o levantamento de diferentes sentimentos e comportamentos que podem estar ligados a novos significados (Rosetti-Ferreira, Amorim, \& Silva, 2004).

O projeto está de acordo com a Resolução 466/12 do CNS e Resolução 510/2016 do CNS e foi iniciado apenas após a apreciação e aprovação pelo Comitê de Ética da Universidade Federal de Pernambuco (CAEE $n^{\circ}$ 72651517.5.0000.5208). Foram assegurados sigilo e anonimato a todos os participantes. Para apresentação dos resultados, foram adotados nomes fictícios (para a pessoa e para a drag queen) no sentido de proteger a identidade das pessoas entrevistadas.

\section{Resultados e Discussão}

Um discurso que atravessa as experiências de todos os entrevistados é o binarismo de gênero (Butler, 2008), parte fundante da matriz sócio-histórica (Rosetti-Ferreira, Amorim \& Silva, 2004). Partindo de uma visão que polariza feminilidade e masculinidade, traçando uma 
linearidade entre homem-masculino e mulher-feminino (Butler, 2008), são gerados efeitos de confusão, estranhamento e até aversão sobre outras formas de manifestação e performatividade de gênero. Nessa direção, a montação se configura de forma marginalizada e é muitas vezes associada a sentidos negativos, tais como vergonha, preconceito, palhaça, degradante, amedrontadora, estranha e incompreensível. Percebeu-se que, em muitos casos, significados negativos foram associados à drag num momento prévio ao contato, marcado pelo estranhamento. Por vezes, a aproximação e aprofundamento com a prática ampliou o olhar dos sujeitos, fazendo surgir novos sentidos e significados, muitos deles positivos, o que mostra uma relação estreita com as temporalidades (Rosetti-Ferreira et al., 2004). É importante ressaltar, contudo, que a presença de sentidos positivos antes da montação, assim como sentidos negativos posteriormente, também é possível, como visto em alguns casos.

Dentre as experiências iniciais relatadas, Marcos conta: "eu tinha muito medo daquelas figuras, sabe? Das drags, eu achava isso muito estranho, não tinha convivência, não entendia o porquê... Por que as pessoas se vestiam, sabe? Não entendia propósito algum naquilo, só achava bem estranho”. Daniel conta que quando passou no vestibular em teatro:

o pessoal brincava muito dizendo 'oa, tu raspasse a cabeça ${ }^{1}$ pra usar peruca é, quando for trabalhar com Cinderela ${ }^{2}$ ?'. Eu (...) xingava, dizia que nunca ia fazer uma palhaçada dessas, dizia que isso era um desperdício, isso só fazia aumentar o preconceito na profissão [de ator].

Todos os participantes dizem ter sido criados em ambientes conservadores, que se propunham à manutenção dos modelos de masculinidade e feminilidade. Apesar de três dos homens entrevistados referirem interesse por objetos associados ao feminino desde a infância, esses desejos confrontaram o sistema sexo-gênero, gerando reações no intuito de reforçá-lo (Butler, 2008). Nesse sentido, observa-se que o discurso da família e da sociedade por vezes se torna o discurso dessas pessoas, que se constroem nesse contexto. Paulo, por exemplo, relata ter experimentado vestidos e sapatos altos de sua mãe de forma escondida quando criança, buscando aproximar-se do universo feminino que o interessava, mas temendo a reação dos pais caso o fizesse abertamente: “já teve épocas de eles [pais de Paulo] procurarem coisas e jogarem fora, e juntarem, assim, juntava roupa, maquiagem, tudo, jogava fora". Observa-se uma tendência a negar e até mesmo excluir elementos do gênero "oposto" na experiência de Paulo, delimitando o que seria ou não possível para ele, enquanto homem. 
Mais tarde, Paulo narra um episódio em que fez uma performance no curso de inglês, ainda antes do surgimento de sua drag queen, Sheyla Áquila:

No halloween, eu vou fazer uma performance, eu disse (...) E fui, fiz. Mas naquele tempo eu tinha muita vergonha, fiquei tão constrangido naquele dia. (...) Quando terminou, eu saí correndo para o banheiro. (...) Aquilo ali foi um grande conflito em mim, de interesses, de valores que me foram passados, e o que eu achava certo e o que tava errado.

Observa-se que Paulo experiencia um conflito devido aos valores presentes na sua constituição enquanto sujeito, que vão de encontro ao seu desejo. Essa demarcação aparece também na narrativa de Vitor, que relata ter sido repreendido por ter usado os shorts da irmã quando criança, e também proibido de brincar com um bambolê, associado a um brinquedo para meninas. Na sua adolescência, Vitor relata um episódio em que teve desejo de interpretar uma personagem mulher, Julieta, numa peça de teatro, mas foi impedido pela professora, pois: "meninos fazem personagens masculinos e meninas fazem personagens femininos". Os homens entrevistados identificam-se enquanto homossexuais, o que gera uma quebra na expectativa da heteronormatividade (Butler, 2008). Dentre os relatos, observa-se que muitos foram repreendidos por tal. Daniel relata:

Aquilo foi início do ensino médio, é... e até então, eu meio que sabia que era gay, mas eu negava pra mim mesmo, né, por diversos motivos, eu cresci na igreja, é então assim, eu negava isso. Né, sempre negando, sempre negando, sempre negando e a Gaga $^{3}$ me deu um estalo [estala os dedos] do tipo, 'eu posso ser eu mesmo'. Aí foi o maior ‘qui qui qui', briga na família, etcétera (...) o melhor que eu pude fazer na época foi abafar o caso e ir pra um retiro da igreja, dizer que eu me converti, que Deus lavou meus pecados e que eu era uma pessoa normal, né?.

Nota-se que Daniel percebe-se em um conflito, uma vez que se identifica como homossexual, mas tem receio de estar fora do padrão heteronormativo, o que também é apontado e atacado pela família. A partir da ideia de pessoa trazida por Rosetti-Ferreira et al. (2004), percebe-se o papel central da interação com o outro e das negociações que são feitas durante o processo de desenvolvimento, que se alteram também a depender do contexto. 
Além da própria pessoa e a família, outras vozes dialogam, como amigos, outras drag queens, a "sociedade" de forma ampla, entre outros.

$\mathrm{Na}$ história dessas pessoas, a decisão de se montar pode ser interpretada como uma renegociação de papéis e assunção de novas posições, como visto em Amorim et al. (2000). Foram traçadas novas relações com o circunscritor de gênero, tão forte no contexto social, e também na matriz sócio-histórica, sendo um elemento que orienta discursos, práticas, instituições, entre outros (Rosetti-Ferreira et al., 2004). A partir de suas experiências, essas pessoas passaram a enxergar a drag queen de uma outra maneira, tecendo outros sentidos e significados a essa prática: arte, paixão, prazer, expressão, realização, reconhecimento, criação, descoberta, transformação, política, luta, liberdade.

Para Marcos, por exemplo, a figura da drag queen passa de incompreensível a uma potência política. Isso envolve um processo de questionamento do status quo, traçando outras possibilidades nem sempre concebidas ou concedidas socialmente:

Eu acho que foi muito produtivo pra mim [se montar], me fez questionar muita coisa, e ter muito mais empatia com outras pessoas, com outras causas, inclusive até com outras minorias mesmo, porque você se vendo como alvo, você acaba percebendo que outras pessoas e outras minorias também são alvos.

É notável, nessa e nas outras histórias, a presença do sofrimento antes, durante e depois da montação, seja pela estrutura social da compreensão do gênero, como também pela dor física envolvida nesse processo. Daniel relata: "a minha estética principal é internacional, eu uso um body, eu uso um espartilho, e ainda boto um espartilho por cima. Então é um aperto muito grande, tá entendendo? é um aperto muito grande, é uma dor muito grande”. Ele traz ainda a prática de aquendar a neca ${ }^{4}$, comum a homens que se vestem de drag queen, relatando que ao estar montado, fica impossibilitado de ir ao banheiro. Contudo, além das dificuldades encontradas, a drag queen também é entendida como um lugar de orgulho, reconhecimento e alegria:

É esse misto de sensações, assim, é realmente a dor de ser o que é, tá entendendo? É uma dor muito grande, mas quando eu chego num evento, quando eu chego nos cantos, que as pessoas falam comigo -- (...) É uma sensação de bater nas suas próprias costas e dizer "Parabéns". (...) É a dor física e é a alegria, de você saber que o seu 
trabalho tá alcançando as pessoas e tendo um impacto positivo nelas, parte do tempo, claro.

Observa-se, portanto, uma mudança significativa na forma de conceber e significar a drag queen. Em alguns casos, essas transformações estão associadas também a pontos de viragem, momentos de ruptura que configuram uma nova forma de pensar e organizar a vida (Mendonça, 2006).

Daniel relata que a participação em uma disciplina sobre teatro asiático configurou-se como um “divisor de águas” para ele:

Até então nunca passou pela minha cabeça me vestir de mulher para a cena... (...) E eu também meio que criei uma barreira em mim desses anos e anos e anos de heteronormatividade forçada, sabe? Eu dizia 'não, eu nunca vou me submeter a isso', mas aí, quando eu comecei a estudar o teatro pelo teatro tradicional eu dei de cara com figuras como (...) o Female Impersonator. Não é nada mais, nada menos, que uma pessoa - que é um homem - que se veste de mulher, e eu me vi apaixonado por essa arte.

A participação nessa disciplina pode ser caracterizada como um ponto de viragem (Oliveira \& Rego, 2006) na vida adulta de Daniel, que alterou sua forma de se relacionar com a figura do homem que se veste de mulher, passando a ter admiração e não vergonha, reconhecendo nessa prática um caráter artístico. Percebe-se também a participação em novos contextos (Rosetti-Ferreira et al., 2004), o da Universidade e o do Teatro, que se diferenciaram da sua vivência familiar, marcada pelo conflito ao ter interesse, na infância, por mídias associadas ao público feminino, como Rouge, Hannah Montana e Floribella; e, posteriormente, se identificar enquanto homossexual. A entrada na universidade também pode ser considerada um ponto de viragem (Oliveira \& Rego, 2006) na história de Vitor. Como trazido anteriormente, ele já expressava desejo de interpretar personagens femininas no teatro, e foi a partir do ensino superior que essa possibilidade lhe foi possível. Ao assistir a série americana Rupaul's Drag Race, percebeu na drag queen uma possibilidade de resgatar a Julieta de uma outra forma: 
Se eu não posso fazer a Julieta lá, no teatro, na escola, na aula de interpretação tal, eu posso tentar fazer isso e fazer alguma coisa com essa Julieta, ela pode fazer parte de mim de alguma forma, e tentar expor isso em algum nível numa performance.

Rosa, por sua vez, reorganiza sua forma de relacionar-se com o mundo após uma sequência de relacionamentos opressivos, tanto por parte da família quanto afetivo-sexuais. Ela relata que após o término com o seu segundo companheiro, estava "num momento em que tava, assim, querendo experimentar tudo, querendo viver tudo, não quero amarras, não quero ninguém dizendo o que eu tenho que fazer, quero voltar a estudar...”. Foi nesse período de "liberdade" que ela refere ter conhecido o atual companheiro, por quem se sente apoiada, e também surgiu a sua drag queen, Kira Heart. Aproximando-se desse universo, ela passou a ter um novo olhar para essa figura, de palhaças a uma forma de arte, possibilidade de expressão e luta:

Hoje, eu vejo que tudo o que ela [Kira Heart] tem, partiu de tudo o que veio daqui [sua história]. Não só a questão artística (...), mas a questão da personalidade dela e pelo o que ela luta, pelo o que eu luto, né? Porque eu acho que pra mim se a drag fosse só... tipo, como há muito tempo foi considerada aquela palhaça ou palhaço que vai animar uma festa, (...) com certeza hoje eu não seria drag (...) Eu acho, assim, que tudo convergiu, tudo o que eu passei, pra a cena drag hoje, né? Que é ser político, né? E é por isso que a Kira Heart existe.

O ponto de viragem aparece na narrativa de Paulo quando toma a decisão de tornar a drag queen uma personagem privada. Ele diz ter começado a se montar com objetivo profissional (trabalhando em campanhas de saúde) e isso passou a enrijecer sua relação com a personagem, não mais tendo prazer com isso:

Foi tudo tão rápido, que eu não tive tempo de saber o que era drag queen (...) Foi aí que eu descobri que a drag queen que eu tinha, que a drag que surgiu, que era uma parte de mim, tinha se transformado num objeto do serviço público.

É nesse momento que Paulo decide reorganizar e resgatar o lugar que ele gostaria que essa drag queen ocupasse, um desejo seu desde a infância: “A drag queen, ela, pra mim, ela é 
algo meu. Onde eu posso desopilar, extravasar os meus sentimentos...”, estando, assim, muito relacionada à liberdade e à expressão.

Atualmente, o fator midiático aparece como um relevante circunscritor na relação com a figura da drag. Entre os elementos que deram maior visibilidade e permitiram uma maior aproximação a essa prática, está o reality show RuPaul's Drag Race, que esteve presente em quatro narrativas. Na história de Marcos, por exemplo, a série apareceu como um mediador desse contato, podendo ser considerada um ponto de viragem:

Começando a assistir Rupaul's Drag Race, eu comecei a entender melhor o entretenimento por trás da $d r a g$, até que entrei em alguns grupos de discussão do programa, e fui vendo outras vivências, de outras pessoas que se montavam também, aí eu fiz: 'hmm, olha que legal, tipo, a desconstrução, lutar contra esse padrão e tal, a gente não precisa ser normativo pra se encaixar em algum lugar', sabe?, (...) E eu fiz, 'não, quer saber? eu vou me montar.

A partir das narrativas, compreende-se que o seriado se tornou um circunscritor no processo de construção da $d r a g$, visto que traça perfis, possibilidades e limites para o que se espera de uma drag queen, assim como orienta práticas. Daniel relata:

O mercado, ele agora tá exigindo que você tenha a estética de Rupaul's Drag Race, tá entendendo? (...) que você seja magra, que você seja bem vestida, que você tenha uma maquiagem cara, super polida, que você esteja usando uma front lace a4, tá entendendo? (...) Eu sou uma drag queen gorda, de pouquíssimos recursos, eu tenho pouquíssimas perucas, eu tenho um vestido só, e fico improvisando looks diversos com ele, tá ligado?

Além do fator micro, apresentado nas trajetórias individuais, compreende-se a série como um elemento da matriz sócio-histórica, tendo em vista a repercussão social e contextual (macro) do reality show. O programa trouxe a figura da drag queen para a cultura mainstream (Bragança, 2018), potencializando sua visibilidade e seu público, acarretando em mudanças na cena drag internacional, orientando práticas e discursos de espectadores, e construindo uma cultura, que se mostra em shows, produções midiáticas, jargões, perfis de drag queens, produtos, entre outros. 
Nas entrevistas, percebe-se que entre os contextos nos quais as drags circulam, está em evidência a cena de festas e bares LGBT. Contudo, elas estão presentes também em teatros, nas universidades onde estudam, em plataformas digitais como o youtube, no contexto da saúde, em academias de ginástica, entre outros, extrapolando o 'lugar comum' esperado que elas estejam presentes. Os circunscritores evidenciam também uma profunda relação com os contextos nos quais as drag queens circulam: percebendo-se fora do padrão estético esperado, Imperatriz Kawaii se coloca no 'limbo' das drag queens, não se sentindo bem-vinda na cena de festas e ocupando mais o espaço do teatro. A partir da RedSig, pode-se também compreender os contextos de forma ampla, não apenas enquanto lugares físicos. Entende-se que pessoa e contextos existem em relação (Rosetti-Ferreira et al., 2004), logo, mudanças nesses elementos os transformam mutuamente:

O momento em que eu me senti livre pra poder dar vazão a isso, com condições, (...) como a condição de liberdade, de já ter minha filha criada, para eu poder fazer o que eu quero; uma certa independência financeira, que me permitiu adquirir as coisas que eu precisei adquirir, fazer as coisas que eu precisava fazer... então, tudo aconteceu, eu acho, no momento certo.

O contexto que Rosa vivencia, associa-se com o início da sua experiência como drag queen, um momento no qual o seu parceiro atual a apoia, a sua filha já está mais velha e ela tem uma maior estabilidade financeira, o que aponta também para circunscritores relacionados à essa experiência (Silva et al., 2004), como o dinheiro, a maternidade e o relacionamento amoroso no qual ela está envolvida.

\section{Minha drag, sua drag: histórias de singularidades e encontros}

A partir dos relatos, compreendeu-se também o processo de montação enquanto um processo de transição (Zittoun, 2007), envolvendo relocações simbólicas e sociais, desenvolvimento de novas habilidades, assim como construção de significados. Percebe-se que "assumir-se" drag queen, para os cinco participantes entrevistados, significou mudanças na forma de se colocar para o outro - seja na família ou na sociedade pensada de forma ampla, desafiando padrões de gênero e expectativas normativas. Observa-se também uma mudança na forma de ver a si mesmo, gerando inclusive mudanças identitárias e elaboração de novos sentidos sobre a figura da drag queen. Além disso, essa prática geralmente veio acompanhada 
de uma circulação em novos contextos, seja em festas, boates, teatro, entre outros, o que está relacionado à relocação social. Nesse processo de entrada em novos contextos, também é negociado um novo lugar com a comunidade $d r a g$, permeado de afetações, conflitos, e novas possibilidades. Sobre isso, Marcos diz:

E isso foi o saldo positivo disso tudo, ter conhecido pessoas que permaneceram e pessoas que se aproximaram muito, que são praticamente a minha segunda família, sabe? Meus melhores amigos hoje em dia são pessoas que eu conheci por conta da minha drag.

Uma prática comum entre as drag queens é o amadrinhamento ${ }^{5}$, mas também há um clima de competição e até mesmo inimizade que surge nesse contexto, entre grupos ou 'famílias'. Sobre sua entrada nessa comunidade, Vitor relata: "foi uma experiência e é uma experiência traumática. Na grande maioria das vezes. Porque a gente fala muito, assim, de preconceito, intolerância, etecetera, e existe uma reprodução disso na própria comunidade LGBT". Contudo, ele também estabelece redes positivas: "Mas eu também posso dizer que eu encontrei pessoas, assim, que eu tenho um sentimento, um carinho muito grande por elas. Que surgiu disso, né? da drag".

Em relação às novas habilidades, podem-se elencar diversos elementos da montação, tais como a maquiagem, o tratamento de perucas e penteados, aquendar a neca, performances, dublagens e dança - como o vogue ${ }^{6}$. Sobre o processo de maquiagem, Rosa relata: "É aprender a relacionar o que a pintura, no sentido de arte, do teu rosto, vai te conectar com a expressão que você quer passar naquele dia, né?”. Há também um fator de ousadia, permitindo-se “experimentar sem medo de errar”, como traz Paulo. Outros conhecimentos adquiridos referem-se ao tensionamento de gênero fomentado pela montação: alguns dos entrevistados referem ter se questionado sobre o que aprenderam de forma polarizada e naturalizante. Daniel desenvolveu sua pesquisa de final de graduação sobre sua drag queen e isso o direcionou para estudos teóricos na área. Rosa, por sua vez, utiliza sua drag queen como uma potência de problematização, buscando conversar com as pessoas sobre padrões de gênero e até ampliando a própria figura da drag queen, usualmente construída por homens cis (reconhecido ao nascer como homem):

a atuação mesmo em que eu vejo sentido, da minha drag queen, assim, é o sentido político, de militância, de desconstruir padrões de gênero, e apesar de eu ser uma 
mulher cis e hétero, até de sexualidade também (...) se eu deixei uma pulguinha atrás da orelha, para mim uma sementinha já é alguma coisa, por que foram as sementes que me fizeram acordar também, né?

A drag queen aparece assim permeada de significações positivas, como forma de visibilidade e empoderamento político (Amanajás, 2015). Entende-se o empoderamento como um instrumento de emancipação política e social coletiva, que visa uma postura de enfrentamento da opressão para combate de situações injustas e equalização de existências no meio social (Birth, 2018). A experiência como drag queen é um campo potencial de transformação e transição, englobando realocações sociais e simbólicas, produção de sentidos, desenvolvimento de habilidades e conhecimentos e até mesmo mudanças identitárias, que muitas vezes tomam corpo na vida adulta, momento importante no processo de desenvolvimento.

No âmbito da psicologia clássica, tem se traçado o desenvolvimento de forma linear, e, nessa perspectiva, a vida adulta tem sido colocada como um período de estabilidade e ausência de mudanças drásticas. Essa leitura faz com que, muitas vezes, não sejam considerados aspectos culturais e singulares da experiência do sujeito, o que limita a observação das possibilidades e multiplicidades presentes no desenvolvimento humano (Oliveira \& Rego, 2006). Contrariamente a essa perspectiva clássica na psicologia do desenvolvimento, a vida adulta, nessa pesquisa, se apresenta como um período não linear, que contém ambiguidades, avanços e retrocessos, rupturas, descontinuidades (Oliveira \& Rego, 2006), e é atravessado pelo acaso, o que permite uma negociação singular de sentidos e significados para cada sujeito.

\section{Considerações Finais}

A partir de uma análise das narrativas foi possível traçar relações entre aspectos diversos da rede de significações da experiência drag queen, ilustrando a interdependência entre esses fatores ao longo do processo e a singularidade com a qual eles se articulam e se constroem em cada caso. A vida adulta se torna o palco no qual é possível ocupar determinados espaços de poder para colocar em prática desejos e curiosidades que, por vezes, remontam à infância. São ressignificados momentos e renegociadas posições, sentidos, visões de mundo. Em todos os casos apresentados, as normas de gênero são contestadas desde cedo, cada um à sua maneira. Contudo, é apenas na vida adulta que essas pessoas tiveram 
autonomia para colocar em prática os seus desejos e curiosidades. Na adultez, foi potencializada a descoberta de si e da drag queen, e nela se experimentam transições, pontos de viragem, renegociações com circunscritores, e a descoberta de outros novos, assim como a descoberta de novos contextos e novas possibilidades de si. A drag queen não se apresenta somente como uma atividade que toma forma em vários momentos do desenvolvimento do sujeito, tais como a vida adulta, mas também se apresenta como uma possibilidade de desenvolvimento.

\section{Referências}

Amanajás, I. (2015). Drag queen: Um percurso histórico pela arte dos atores transformistas. Revista Belas Artes, 6(16), 1-23. Recuperado de http://www.belasartes.br/revistabelasartes/downloads/artigos/16/drag-queen-umpercurso-historico-pela-artedos-atores-transformistas.pdf

Amorim, K. S., Vitoria, T., \& Rossetti-Ferreira, M. C. (2000). Rede de significações: Perspectiva para análise da inserção de bebês na creche. Cadernos de Pesquisa, (109), 115-144. doi:10.1590/S0100-15742000000100006

Bragança, L. (2018). Desaquendando a história drag: No mundo, no Brasil e no Espírito Santo. Vitória, ES: Edição Independente.

Birth, J. (2018). O que é Empoderamento?. Belo Horizonte, MG: Letramento.

Bruner, J. (2004). Life as narrative. Social research: An international quarterly, 71(3), 691710. Recuperado de https://muse.jhu.edu/article/527352/summary

Butler, J. (2008). Problemas de gênero: Feminismo e subversão da identidade. Rio de Janeiro: Civilização Brasileira.

Carloto, C. M. (2001). O conceito de gênero e sua importância para a análise das relações sociais. Serviço social em revista, 3(2), 201-213. Recuperado de http://www.uel.br/revistas/ssrevista/n2v3.pdf\#page=83

Jesus, B., Ramires, L., Unbehaum, S., \& Cavasin, S. (2008). Diversidade Sexual na Escola: Uma metodologia de trabalho com adolescentes e jovens (Ed. especial, rev. e ampl.). São Paulo: ECOS - Comunicação em sexualidade. Recuperado de http://www.acaoeducativa.org.br/fdh/wp-content/uploads/2015/11/DiversidadeSexual-na-Escola-uma-metodologia-de-trabalho-CORSA-e-ECOS-2008-1.pdf

Jesus, J. G. (2012). Orientações sobre identidade de gênero: Conceitos e termos: Guia técnico sobre pessoas transexuais, travestis e demais transgêneros, para formadores 
Ligia Ribeiro Ferreira, Renata Lira dos Santos Aléssio

de opinião. $\quad$ Brasília: Autor. Recuperado de https://files.cercomp.ufg.br/weby/up/16/o/ORIENTA\%C3\%87\%C3\%95ES_POPULA \%C3\%87\%C3\%830_TRANS.pdf?1334065989

Louro, G. L. (2004). Marcas do corpo, marcas de poder. In G. L. Louro (Org.), Um corpo estranho: Ensaios sobre sexualidade e teoria queer (pp. 75-90). Belo Horizonte: Autêntica.

Mendonça, L. (2006). Ciclos de vida: Desenvolvimento psicológico e constituição de subjetividades (Projeto de iniciação científica). Universidade de São Paulo, Faculdade de Educação, São Paulo, SP, Brasil. Recuperado de http://www.geocities.ws/lucmend/ciclosvida.pdf

Oliveira, M. K., \& Rego, T. C. (2006). Desenvolvimento psicológico e constituição de subjetividades: Ciclos de vida, narrativas autobiográficas e tensões da contemporaneidade. Pro-posições, 17(2), 119-138. Recuperado de https://periodicos.sbu.unicamp.br/ojs/index.php/proposic/article/view/8643631

Rossetti-Ferreira, M. C., Amorim, K. D. S., \& Silva, A. D. (2004). Rede de significações: Alguns conceitos básicos. In M. C. Rossetti-Ferreira et al. (Orgs.), Rede de significações e o estudo do desenvolvimento humano (pp. 23-33). Porto Alegre: ArtMed.

Silva, A. D., Rossetti-Ferreira, M. C., \& Carvalho, A. M. A. (2004). Circunscritores: Limites e possibilidades no desenvolvimento. In M. C. Rossetti-Ferreira et al. (Orgs.), Rede de significações e o estudo do desenvolvimento humano (pp. 81-93). Porto Alegre: ArtMed.

Smolka, A. L. B. (2004). Sobre significação e sentido: Uma contribuição à proposta de Rede de Significações. In M. C. Rossetti-Ferreira et al. (Orgs.), Rede de significações e o estudo do desenvolvimento humano (pp. 35-49). Porto Alegre: ArtMed.

Vencato, A. P. (2010). Confusões e estereótipos: O ocultamento de diferenças na ênfase de semelhanças entre transgêneros. Cadernos AEL, 10(18/19). Recuperado de https://www.ifch.unicamp.br/ojs/index.php/ael/article/view/2513/1923

Vinuto, J. (2014). A amostragem em bola de neve na pesquisa qualitativa: Um debate em aberto. Temáticas, 22(44), 203-220. doi:10.20396/temáticas.v22i44.10977

Zimovski, T., \& Caeiro, M. (2016). Contribuições da psicossociologia na compreensão da constituição da(s) identidade(s) drag queen. Anais do Congresso Brasileiro de Estudos Organizacionais, Porto Alegre, RS, Brasil, 4. Recuperado de https://anaiscbeo.emnuvens.com.br/cbeo/article/view/92/84 
Zittoun, T., Duveen, G., Gillespie, A., Ivinson, G., \& Psaltis, C. (2003). The use of symbolic resources in developmental transitions. Culture \& Psychology, 9(4), 415-448. doi:10.1177/1354067X0394006

Zittoun, T. (2007). Symbolic resources and responsibility in transitions. Young, 15(2), 193211. doi:10.1177/110330880701500205

\section{Endereço para correspondência}

\section{Ligia Ribeiro Ferreira}

Rua Clóvis Beviláqua, 163 apto 1004, Madalena, Recife - PE, Brasil. CEP 50710-330

Endereço eletrônico: ligia.rf1@gmail.com

\section{Renata Lira dos Santos Aléssio}

Centro de Filosofia e Ciências Humanas

Av. Acadêmico Hélio Ramos, s/n, $9^{\circ}$ andar do CFCH, Cidade Universitária, Recife - PE, Brasil. CEP 50670-901 Endereço eletrônico: renatalir@gmail.com

Recebido em: 05/07/2019

Reformulado em: 07/03/2020

Aceito em: 27/04/2020

\section{Notas}

* Mestranda em Psicologia na Universidade Federal de Pernambuco.

** Professora Adjunta do Departamento de Psicologia da Universidade Federal de Pernambuco.

${ }^{1}$ Prática comum aos homens após serem aprovados no vestibular.

${ }^{2}$ Personagem interpretada pelo artista Jeison Wallace, transformista e humorista que se tornou popular na TV do Nordeste.

${ }^{3}$ Refere-se a cantora americana Lady Gaga, ícone da cultura pop, e referência na cultura LGBT.

${ }^{4}$ Expressão que significa esconder o pênis, com o intuito de construir uma figura mais semelhante a uma vagina.

${ }^{5}$ Nesse contexto, refere-se ao processo no qual uma drag que tem mais experiência acolhe uma drag iniciante e lhe auxilia no processo de construção da personagem, na maquiagem, entre outros. Pode ocorrer de que as drags da mesma 'família' tenham todas o mesmo sobrenome, indicando que fazem parte do mesmo grupo. É uma prática que remonta à cultura Ballroom. Para mais informações, indica-se o documentário "Paris is Burning".

${ }^{6}$ Dança cujos passos imitam as poses geométricas das modelos em capas de revista de moda, especialmente a revista 'Vogue'. Surgiu nos EUA também associada à cultura Ballroom e é bastante difundida no meio LGBT.

Este artigo de revista Estudos e Pesquisas em Psicologia é licenciado sob uma Licença Creative Commons Atribuição-Não Comercial 3.0 Não Adaptada. 